\title{
KEPATUHAN MINUM OBAT PADA PASIEN DIABETES MELITUS TIPE 2 DI WILAYAH KERJA PUSKESMAS TABANAN II TAHUN 2019
}

\author{
Ida Ayu Putu Mita Diantari K.*, I Made Sutarga \\ Program Studi Sarjana Kesehatan Masyarakat, Fakultas Kedokteran, Universitas Udayana \\ *email : mitadiantari87@gmail.com
}

\begin{abstract}
ABSTRAK
Presentase kematian akibat diabetes di Indonesia merupakan yang tertinggi kedua setelah Sri Lanka. Salah satu perilaku pengendalian DM yaitu kepatuhan minum obat. Kepatuhan pengobatan yang rendah dapat mengakibatkan peningkatan penyakit komplikasi dan risiko rawat inap. Puskesmas Tabanan II merupakan puskesmas yang memiliki jumlah kunjungan pasien DM tipe 2 terbanyak di Kabupaten Tabanan. Penelitian ini bertujuan untuk mengetahui tingkat kepatuhan minum obat pada pasien DM tipe 2 di wilayah kerja Puskesmas Tabanan II. Desain penelitian merupakan observasional deskripstif dengan menggunakan rancangan studi cross sectional untuk menggambarkan kepatuhan minum obat pada pasien DM tipe 2 di wilayah kerja Puskesmas Tabanan II. Teknik pengambilan sampel dilakukan dengan metode systematic random sampling. Penelitian ini menggunakan analisis inferensial berupa analisis univariat dan analisis bivariat. Sampel dalam penelitian ini yaitu pasien DM tipe 2 di wilayah kerja Puskesmas Tabanan II. Hasil analisis memperlihatkan bahwa dari 69 responden, 52 responden $(75,36 \%)$ dikategorikan patuh dan 17 responden (24,64\%) sisanya dikategorikan tidak patuh. Hal ini disebabkan oleh beberapa faktor yaitu umur, jenis kelamin, tingkat pendidikan, pekerjaan, jenis obat yang dikonsumsi, lama menderita DM, dan dukungan keluarga. Disarankan agar puskesmas dapat meningkatkan edukasi terkait pentingnya dukungan keluarga kepada keluarga pasien DM tipe 2 agar kepatuhan minum obat dapat meningkat.
\end{abstract}

Kata Kunci : Diabetes Melitus, Kepatuhan Minum Obat, Dukungan Keluarga

\section{ABSTRACT}

The percentage of deaths from diabetes in Indonesia is the second highest after Sri Lanka. One of the behaviors for controlling diabetes mellitus is adherence with taking madication. Adherence with treatment that can increase risk of complications and the risk of hospitalization. Puskesmas Tabanan II is a health center that has the highest number of type 2 DM patient visits in Tabanan Regency. This study aims to determine the success rate of taking medication in type $2 \mathrm{DM}$ patients in the working area of Puskesmas Tabanan II. The research design was descriptive observational using a cross sectional study design to describe medication adherence in type 2 DM patients in the Puskesmas Tabanan II working area in 2019. The sampling technique was a systematic random sampling method. This study use inferential analysis in the form of univariate analysis and bivariate analysis. The sample of this study is type 2 DM patients in the Puskesmas Tabanan II working area. The results of the analysis show that of 69 respondents, 52 respondents (75.36\%) were categorized as obedient and 17 respondents (24.64\%) were categorized as non-compliant. This is caused by several factors, namely age, sex, level of education, occupation, type of medication consumed, duration of suffering from diabetes, and family support. It is recommended that Puskesmas can increased education regarding the importance of family support to families of type $2 \mathrm{DM}$ patients so that adherence to medication, especially taking medication can be increased.

Keywords: Diabetes Mellitus, Adherence with Taking Medication, Family Support

\section{PENDAHULUAN}

Diabetes Melitus (DM) adalah penyakit gangguan metabolic menahun akibat pancreas tidak memproduksi cukup insulin atau tubuh tidak dapat menggunakan insulin yang di produksi secara efektif. Insulin adalah hormon yang mengatur keseimbangan kadar gula darah. akibatnya terjadi peningkatan konsentrasi glukosa di dalam darah (hiperglikemia) (Depkes, 2014).

Indonesia menempati peringkat ke-7 dunia untuk prevalensi penderita diabetes tertinggi di dunia bersama dengan China, India, Amerika Serikat, 
Brazil, Rusia, dan Meksiko dengan jumlah estimasi orang dengan diabetes sebesar 10 juta pada tahun 2015 (IDF, 2015). Presentase kematian akibat diabetes di Indonesia merupakan yang tertinggi kedua setelah Sri Lanka. Prevalensi orang dengan diabetes di Indonesia menunjukkan kecenderungan meningkat yaitu dari 5,7\% di tahun 2007 menjadi 6,9\% di tahun 2013 (WHO, 2016). DM mengalami peningkatan yang mulanya 1,1\% pada tahun 2007 menjadi 2,1\% di tahun 2013. Proporsi penduduk > 15 tahun dengan DM adalah 6,9\% (Riskesdas, 2013).

Menurut Dinkes Provinsi Bali (2017), DM tipe 2 menempati posisi ke- 9 dalam 10 penyakit yang paling banyak di Provinsi Bali dengan total kasus sebesar 16.254. Menurut Dinkes Kabupaten Tabanan (2016), DM tipe 2 juga menduduki peringkat ke-9 dalam 10 penyakit yang paling banyak dengan total kasus sebanyak 6.486, yang terdiri dari 2.926 kasus diderita oleh laki-laki dan 3.560 diderita oleh perempuan.

DM terus mengancam kehidupan masyarakat, sekitar $12-20 \%$ penduduk dunia diperkirakan mengidap DM dan setiap 10 detik di dunia satu orang meninggal akibat komplikasi yang ditimbulkan. Semakin banyaknya komplikasi yang terjadi akibat DM, Perkumpulan Endokrinologi Indonesia (PERKENI) telah mengeluarkan konsensus penatalaksanaan DM tahun 2011 yaitu dengan membuat 4 pilar sebagai penatalaksanaan DM tipe 2 yaitu edukasi, latihan jasmani, terapi nutrisi dan intervensi farmakologis

(PERKENI,

2011).

Penatalaksanaan farmakologi merupakan salah satu pilar penatalaksanaan DM tipe 2 yang sangat penting. Terapi farmakologi diberikan apabila setelah dilakukan latihan jasmani dan terapi nutrisi, tetapi glukosa darah belum terkendali dengan baik, maka pemberian obat hipoglikemi harus diberikan sesuai dengan indikasi. Terapi pengobatan yang baik dan benar akan memberikan manfaat bagi pasien, dari segi kesehatan atau kesembuhan penyakit yang diderita.

Kepatuhan minum obat pada pasien diabetes melitus penting untuk mencapai tujuan pengobatan dan efektif untuk mencegah komplikasi pada penyakit diabetes melitus terutama bagi pasien yang harus mengkonsumsi obat dalam jangka waktu yang lama, bahkan seumur hidupnya (Sasmito, 2007). Kepatuhan pengobatan yang rendah dapat mengakibatkan peningkatan risiko biaya perawatan, peningkatan penyakit komplikasi dan risiko rawat inap (Srikartika dkk, 2016). Berbagai pendekatan dapat dilakukan untuk menggambarkan kepatuhan penderita yaitu metode langsung yang meliputi observasi langsung terhadap terapi penderita, pengukuran aspek biologis dalam meliputi laporan diri pasien atau kuisioner, perhitungan jumlah pil, pengambilan obat kembali, pemantauan obat secara elektronik, dan penilaian diri penderita terhadap respon (Tan et al, 2009).

Kepatuhan pada penderita DM ditunjukkan dengan kemampuan melaksanakan cara pengobatan yang 
disarankan oleh petugas kesehatan. Kemampuan penderita DM mengontrol kehidupannya dapat mempengaruhi tingkat kepatuhan (Trekas 1984 dalam Tombokan, dkk 2015). Kepatuhan pengobatan yang rendah dapat mengakibatkan peningkatan risiko biaya perawatan, peningkatan penyakit komplikasi dan risiko rawat inap (Srikartika dkk, 2016). Berbagai pendekatan dapat dilakukan untuk menggambarkan kepatuhan penderita yaitu metode langsung yang meliputi observasi langsung terhadap terapi penderita, pengukuran aspek biologis dalam meliputi laporan diri pasien atau kuisioner, perhitungan jumlah pil, pengambilan obat kembali, pemantauan obat secara elektronik, dan penilaian diri penderita terhadap respon (Tan et al, 2009).

Perilaku tidak patuh pada umumnya akan meningkatkan risiko yang terkait dengan masalah kesehatan dan semakin memperburuk penyakit penderita. Kesulitan-kesulitan yang dialami dalam pengobatan berkala menyebabkan penderita DM dapat menjadi tidak patuh dalam mengontrol kadar gulanya (Pratita, 2012). Meningkatnya kepatuhan pada penderita DM merupakan hasil dari interaksi antara lingkungan social, pasien, dan penyedia layanan kesehatan. Puskesmas Tabanan II merupakan puskesmas yang memiliki jumlah kunjungan pasien DM Tipe 2 terbanyak di Kabupaten Tabanan dengan jumlah kunjungan pada tahun 2017 sebesar 419 dan di tahun 2018 sebanyak 486 (Dinkes Kabupaten Tabanan, 2017\&2018).

\section{METODE PENELITIAN}

Desain penelitian yang digunakan adalah observasional deskripstif dengan menggunakan rancangan studi cross sectional untuk menggambarkan kepatuhan minum obat pada pasien DM tipe 2 di wilayah kerja Puskesmas Tabanan II tahun 2019. Penelitian dilaksanakan di wilayah kerja Puskesmas Tabanan II dari bulan Maret-Mei 2019. Sampel dalam penelitian ini yaitu pasien DM tipe 2 yang berkunjung ke Puskesmas Tabanan II periode JanuariDesember 2018. Teknik pengambilan sampel dilakukan dengan metode systematic random sampling. Data primer diperoleh melalui wawancara menggunakan kuisioner yang meliputi karakteristik responden (umur, jenis kelamin, pendidikan, pekerjaan, lama DM, obat yang dikonsumsi), dukungan keluarga, kepatuhan minum obat. Data sekunder diperoleh dari register rawat jalan Puskesmas Tabanan II periode JanuariDesember 2018 yang meliputi data pasien DM tipe 2. Penelitian ini akan menggunakan analisis inferensial berupa analisis univariat dan analisis bivariat. 
HASIL

Analisis Univariat Karakteristik Responden

Tabel 1. Karakteristik Pasien DM Tipe 2 di Wilayah Kerja Puskesmas Tabanan II Tahun 2019

\begin{tabular}{lcc}
\hline \multicolumn{1}{c}{ Variabel } & Frekuensi & $\%$ \\
\hline Umur & 33 & \\
$\quad<60$ tahun & 36 & 47,83 \\
$\quad \geq 60$ tahun & & 53,17 \\
$\begin{array}{l}\text { Jenis Kelamin } \\
\quad \text { Laki-laki }\end{array}$ & 37 & 53,62 \\
$\quad$ Perempuan & 32 & 46,38 \\
Tingkat Pendidikan & & \\
$\quad$ Rendah & 45 & 65,22 \\
$\quad$ Tinggi & 24 & 34,78 \\
Pekerjaan & & \\
$\quad$ Bekerja & 39 & 56,52 \\
$\quad$ Tidak Bekerja & 30 & 43,48 \\
Lama DM & & \\
$\quad \leq 5$ tahun & 18 & 26,09 \\
$\quad>5$ tahun & 51 & 73,91 \\
Jenis Obat yang Dikonsumsi & & 66,67 \\
1 jenis & 46 & 33,33 \\
\hline jenis & 23 & 56,
\end{tabular}

Penelitian dilakukan terhadap 69 responden yang menderita penyakit DM tipe 2 yang diambil dari register rawat jalan di Puskesmas Tabanan II. Berdasarkan data tabel 5.1 diatas, umur dikategorikan menjadi dua kelompok yaitu $<60$ tahun yang berjumlah 33 responden $(47,83 \%)$ serta $\geq 60$ tahun yang berjumlah 36 responden (53,17\%). Pada karakteristik jenis kelamin, diketahui responden yang berjenis kelamin laki-laki berjumlah 37 responden $(53,62 \%)$ dan responden berjenis kelamin perempuan berjumlah 32 responden (46,38\%). Untuk tingkat pendidikan, terlihat bahwa sebagian besar responden memiliki tingkat pendidikan rendah (tidak sekolah, tidak tamat SD, SD, SMP) yaitu sebanyak 45 responden (65,22\%). Untuk karakteristik pekerjaan, sebanyak 39 responden $(56,52 \%)$ bekerja dan sebanyak 30 responden $(43,48 \%)$ tidak bekerja. Dilihat dari lama menderita DM, diperoleh hasil bahwa sebanyak 51 responden $(73,91 \%)$ telah menderita DM lebih dari 5 tahun. Untuk jenis obat yang dikonsumsi, dapat dilihat bahwa 46 responden (66,67\%) mengonsumsi 1 jenis obat saja dan 23 responden lainnya (33,33\%) mengonsumsi 2 jenis obat. 
Arc. Com. Health Desember 2019

ISSN: 2527-3620

Vol. 6 No. $2: 40$ - 50

\section{Analisis Univariat Dukungan Keluarga}

Tabel 2. Gambaran Dukungan Keluarga Pasien DM Tipe 2 di Wilayah Kerja Puskesmas Tabanan II Tahun 2019

\begin{tabular}{lcc}
\hline \multicolumn{1}{c}{ Dukungan Keluarga } & Frekuensi & \% \\
\hline Kurang & 32 & 46,38 \\
Baik & 37 & 53,62 \\
\hline Total & 69 & 100,00 \\
\hline
\end{tabular}

Dukungan keluarga ditentukan berdasarkan total nilai responden dari jawaban pertanyan-pertanyaan yang menjadi indicator. Berdasarkan data diatas, didapatkan hasil bahwa sebanyak 37 responden $(53,62 \%)$ memperoleh dukungan keluarga yang baik.

\section{Analisis Univariat Kepatuhan Minum Obat}

Tabel 3. Gambaran Kepatuhan Minum Obat Pada Pasien DM Tipe 2 di Wilayah Kerja Puskesmas Tabanan II Tahun 2019

\begin{tabular}{lcc}
\hline \multicolumn{1}{c}{ Kepatuhan Minum Obat } & Frekuensi & $\mathbf{\%}$ \\
\hline Patuh & 52 & 75,36 \\
Tidak patuh & 17 & 24,64 \\
\hline Total & 69 & 100 \\
\hline
\end{tabular}

Tingkat kepatuhan minum obat responden ditentukan berdasarkan total nilai responden dari jawaban pertanyaanpertanyaan yang menjadi indicator. Berdasarkan tabel 5.5 diatas, didapatkan

\section{Analisis Bivariat Karakteristik Responden}

Tabel 4. Hasil Bivariat Karakteristik Responden hasil bahwa sebanyak 52 responden $(75,36 \%)$ patuh meminum obat dan sebanyak 17 responden (24,64\%) tidak patuh meminum obat.

\section{Variabel}

\begin{tabular}{ccc} 
Patuh & Tidak Patuh & Total \\
\hline $\mathbf{f}(\%)$ & $\mathbf{f}(\%)$ & $\mathbf{f}(\%)$
\end{tabular}

\section{Umur}

$\begin{array}{llcl}<60 \text { tahun } & 21(63,64) & 12(36,36) & 33(100) \\ \geq 60 \text { tahun } & 31(86,11) & 5(13,89) & 36(100)\end{array}$

Jenis Kelamin 


\section{Laki-laki}

Perempuan

Tingkat Pendidikan

Rendah

Tinggi

Pekerjaan

Bekerja

Tidak Bekerja

Lama DM

$$
\begin{aligned}
& \leq 5 \text { tahun } \\
& >5 \text { tahun }
\end{aligned}
$$

Jenis Obat yang Dikonsumsi
$30(81,08)$

$22(68,75)$

$37(82,22)$

$15(62,50)$

$29(74,36)$

$23(76,67)$

$10(55,56)$

$42(82,35)$

$$
7(18,92)
$$

$10(31,25)$
37 (100)

$32(100)$

$8(17,78)$

$45(100)$

$9(37,50)$

$24(100)$

39 (100)

$30(100)$

$7(23,33)$

$8(44,44)$

$18(100)$

$9(17,65)$ $\begin{aligned} & 1 \text { jenis } \\ & 2 \text { jenis }\end{aligned}$
Tabel diatas menunjukkan bahwa
dari seluruh responden yang berusia <60
tahun sebanyak 21 responden $(63,64 \%)$
terkategori patuh minum obat dan 12
responden $(36,36 \%)$ lainnya terkategori tidak patuh. Pada responden yang berusia $\geq 60$ tahun diketahui sebanyak 31 responden $(86,11 \%)$ terkategori patuh minum obat dan 5 responden (13,89\%) lainnya terkategori tidak patuh. Berdasarkan jenis kelamin, didapatkan hasil bahwa responden yang berjenis kelamin laki-laki sebanyak 30 responden $(81,08 \%)$ terkategori patuh minum obat dan 7 responden $(18,92 \%)$ lainnya terkategori tidak patuh. Sedangkan responden yang berjenis kelamin perempuan sebanyak 22 responden $(68,75 \%)$ terkategori patuh minum obat dan 10 responden $(31,25 \%)$ lainnya terkategori tidak patuh.Berdasarkan tingkat pendidikan, responden dengan tingkat pendidikan rendah (tidak sekolah, tidak tamat SD, SD, SMP) terdapat sebanyak 37 responden $(82,22 \%)$ terkategori patuh
$35(76,09) \quad 11(23,91) \quad 46(100)$

$17(73,91) \quad 6(26,09) \quad 23(100)$

minum obat dan 8 responden $(17,78 \%)$ lainnya terkategori tidak patuh. Sedangkan responden dengan tingkat pendidikan tinggi (SMA dan Perguruan Tinggi) sebanyak 15 responden (62,50\%) terkategori patuh minum obat dan 9 responden $(37,50 \%)$ lainnya terkategori tidak patuh. Berdasarkan jenis pekerjaan, dari 39 responden yang bekerja, 29 responden (74,36\%) terkategori patuh minum obat dan 10 responden $(25,64 \%)$ lainnya terkategori tidak patuh. Sedangkan 30 responden lainnya yang tidak bekerja, sebanyak 23 responden $(76,67 \%)$ terkategori patuh minum obat dan 7 responden (23,33\%) lainnya terkategori tidak patuh. Dilihat dari lamanya menderita DM, dari 18 responden yang menderita DM $\leq 5$ tahun, sebanyak 10 responden $(55,56 \%)$ terkategori patuh minum obat dan 8 responden (44,44\%) lainnya terkategori tidak patuh. Sedangkan 51 responden lainnya yang menderita DM $>5$ tahun, sebanyak 42 responden $(82,35 \%)$ terkategori patuh minum obat dan 9 
responden $(17,65 \%)$ lainnya terkategori tidak patuh. Dari jenis obat yang dikonsumsi, dari 46 responden yang mengonsumsi 1 jenis obat diabetes, sebanyak 35 responden (76,09\%) terkategori patuh minum obat dan 11 responden
(23,91\%) lainnya terkategori tidak patuh. Dan 23 responden lainnya yang mengonsumsi 2 jenis obat diabetes, sebanyak 17 responden $(73,91 \%)$ terkategori patuh minum obat dan 6 responden $(26,09 \%)$ lainnya terkategori tidak patuh.

\section{Analisis Bivariat Dukungan Keluarga}

Tabel 5. Hasil Bivariat Dukungan Keluarga

\begin{tabular}{lccc}
\hline Variabel & Patuh & Tidak Patuh & Total \\
\cline { 2 - 4 } & $\mathbf{f ( \% )}$ & $\mathbf{f ( \% )}$ & $\mathbf{f}(\mathbf{\%})$ \\
\hline $\begin{array}{l}\text { Dukungan Keluarga } \\
\text { Kurang }\end{array}$ & $23(71,88)$ & $9(28,13)$ & $32(100)$ \\
Baik & $29(78,38)$ & $8(21,62)$ & $37(100)$ \\
\hline
\end{tabular}

Dari data diatas, dapat dilihat bahwa dari 37 responden yang memiliki dukungan keluarga yang baik, sebanyak 29 responden $(78,38 \%)$ diantaranya terkategori patuh minum obat dan 8 responden $(21,62 \%)$ lainnya terkategori tidak patuh. Sedangkan dari 32 responden yang memiliki dukungan keluarga yang kurang, 23 responden (71,88\%) diantaranya terkategori patuh minum obat dan 9 responden $(28,13 \%)$ lainnya terkategori tidak patuh.

\section{DISKUSI}

Hasil analisis memperlihatkan bahwa dari 69 responden, 52 responden $(75,36 \%)$ dikategorikan patuh dan 17 responden (24,64\%) sisanya dikategorikan tidak patuh. Hal ini disebabkan oleh beberapa faktor yaitu umur, jenis kelamin, tingkat pendidikan, pekerjaan, jenis obat yang dikonsumsi, lama menderita DM, dan dukungan keluarga.

Berdasarkan data umur, hasil analisis bivariat memperlihatkan bahwa responden yang berusia $\geq 60$ tahun $(86,11 \%)$ lebih patuh minum obat daripada responden yang berusia $<60$ tahun $(63,64 \%)$. Hal ini dikarenakan responden yang berusia $\geq 60$ tahun sebagian besar sudah tidak bekerja, sehingga aktivitas yang dilakukan lebih sedikit daripada responden yang berusia $<60$ tahun yang merupakan masih usia produktif, sehingga responden yang berusia $\geq 60$ tahun lebih patuh dalam meminum obat.

Berdasarkan data jenis kelamin, hasil bivariat memperlihatkan bahwa responden dengan jenis kelamin laki-laki (81,08\%) lebih patuh minum obat daripada responden dengan jenis kelamin perempuan $(68,75 \%)$. Hal ini disebabkan 
karena responden wanita mengaku memiliki aktivitas yang padat sehingga membuatnya lupa minum obat dan terlambat menebus obat. Selain itu responden laki-laki memiliki sikap berobat yang baik dibandingkan responden perempuan dan responden laki-laki cenderung lebih peduli terhadap penyakitnya sehingga membuat responden laki-laki lebih rajin olahraga, mengatur pola diet, serta lebih teratur minum obat (Romadona, 2011). Demikian pula dengan penelitian Majed H., dkk (2014), menunjukan mayoritas pasien patuh adalah laki-laki sebesar 51,4\%. Penelitian lain yang dilakukan oleh Mokolomban (2018) juga menunjukkan 38,89\% pasien laki-laki lebih patuh daripada perempuan 37,04\%.

Berdasarkan data tingkat pendidikan, hasil bivariat memperlihatkan responden dengan pendidikan rendah $(82,22 \%)$ lebih patuh minum obat daripada responden dengan pendidikan tinggi (62,50\%). Hasil penelitian ini menunjukkan bahwa tingkat kepatuhannya tidak dapat dibandingkan. Karena, distribusi pasien yang jauh lebih besar terletak pada tingkat pendidikan rendah (tidak sekolah, tidak tamat SD, SD, SMP) 65,22\%, dengan tingkat kepatuhannya $82,22 \%$. Berdasarkan penelitian ini, pasien ditingkat pendidikan rendah menilai bahwa kesehatan merupakan suatu hal yang lebih penting. Dengan patuh mengonsumsi obat maka akan membantu meningkatkan kesehatan. Hasil penelitian yang dilakukan oleh Mokolomban (2016) juga menunjukkan bahwa tingkat pendidikan kepatuhan pasien berpendidikan menengah $(62,22 \%)$ lebih tinggi daripada pasien berpendidikan tinggi (26,67\%). Hal ini menunjukkan bahwa tingkat pendidikan tidak berpengaruh pada kepatuhan pasien.

Berdasarkan data jenis pekerjaan, hasil bivariat memperlihatkan responden yang tidak bekerja $(76,67 \%)$ lebih patuh minum obat daripada responden yang bekerja (74,36\%). Berdasarkan penelitian ini, pasien tidak bekerja lebih patuh mengonsumsi obat, karena pasien ini tidak memiliki banyak kesibukan untuk dikerjakan, sehingga memiliki waktu untuk pergi mengambil obat dan mengingat waktu meminum obatnya. Penelitian yang sama juga ditunjukkan oleh Mokolomban (2016) dengan $44,44 \%$ pasien yang tidak bekerja lebih patuh dalam mengonsumsi obat daripada yang bekerja sebagai IRT dan wiraswasta. Demikian pula hasil penelitian Adisa., dkk (2009) yang dilakukan di Nigeria menyebutkan bahwa pasien yang tidak aktif bekerja memiliki kepatuhan yang lebih tinggi dibandingkan dengan pasien yang aktif bekerja. Menurut Notoatmodjo (2007), orang yang bekerja cenderung memiliki sedikit waktu untuk mengunjungi fasilitas kesehatan, sehingga menurunkan tingkat kepatuhannya dalam mengonsumsi obat.

Berdasarkan data lama menderita DM, hasil univariat memperlihatkan responden yang lama menderita DM >5 tahun $(73,91 \%)$ lebih banyak daripada responden yang lama menderita DM $\leq 5$ tahun (26,09\%). Hasil bivariate memperlihatkan hasil responden yang lama menderita DM >5 
tahun $(82,35 \%)$ lebih patuh minum obat daripada responden yang lama menderita $\mathrm{DM} \leq 5$ tahun (55,56\%). Durasi atau lamanya penyakit berpengaruh terhadap kepatuhan pengobatan. Berdasarkan penelitian ini, pasien patuh karena sudah lama menderita DM dan ingin memperpanjang kualitas hidupnya.

Berdasarkan data jenis obat, hasil univariat memperlihatkan responden yang mengonsumsi 1 jenis obat (66,67\%) lebih banyak daripada responden yang mengonsumsi 2 jenis obat (33,33\%). Jenis obat yang dikonsumsi responden yaitu Metformin dan Glimepiride. Hasil bivariat memperlihatkan responden yang mengonsumsi 1 jenis obat (Metformin atau Glimepiride) (76,09\%) lebih banyak daripada responden yang mengonsumsi 2 jenis obat (Metformin dan Glimepiride) (73,91\%). Kepatuhan berkorelasi dengan jumlah dosis setiap hari dari semua obat yang diresepkan. Tingkat kepatuhan menurun apabila jumlah dosis harian meningkat. Dengan demikian, penyederhanaan frekuensi dosis obat dapat meningkatkan kepatuhan. Pasien diabetes melitus tipe 2 dengan penyakit penyerta secara tidak langsung akan mengonsumsi jenis obat yang lebih kompleks. Jenis obat yang kompleks seperti jumlah obat, frekuensi pemberian, bentuk sediaan, dan juga instruksi pemberian obat yang khusus dapat memicu ketidakpatuhan. Hasil penelitian yang dilakukan oleh Handayani (2012) mengatakan bahwa, dari 71 responden sebanyak 40 (85\%) pasien lebih patuh mengonsumsi obat dengan jumlah $<5$ jenis obat, yang lainnya pada kategori patuh rendah dan sedang. Secara tidak langsung pasien diabetes melitus tipe 2 dengan penyakit penyerta akan mengonsumsi jenis obat yang lebih kompleks. Jenis obat yang kompleks dapat memicu ketidakpatuhan (Rosdianah, 2016).

Berdasarkan dukungan keluarga, hasil analisis univariat memperlihatkan dukungan keluarga yang baik (53,62\%) lebih banyak daripada dukungan keluarga yang kurang baik (46,38\%). Hasil analisis bivariat memperlihatkan dukungan keluarga yang baik (78,38\%) lebih patuh minum obat daripada dukungan keluarga yang kurang baik (71,88\%). Walaupun hasil analisis dari dukungan keluarga yang baik lebih banyak daripada dukungan keluarga yang kurang baik, namun hasil keduanya tidak menunjukkan perbedaan yang signifikan. Berdasarkan hal tersebut, dukungan keluarga tidak dapat dibandingkan. Namun, penelitianpenelitian sebelumnya yang meneliti mengenai dukungan keluarga dan kepatuhan minum obat, seperti Kristianingrum (2011) mengatakan bahwa 43,33\% subjek memiliki tingkat kepatuhan minum obat yang tinggi, 56,67\% subjek memiliki tingkat kepatuhan minum obat yang sedang, dan tidak ada (0\%) subjek yang memiliki tingkat kepatuhan minum obat yang rendah. Berdasarkan hasil tersebut dapat dinyatakan bahwa sebagian besar subjek merasakan tingkat dukungan keluarga yang tinggi. 


\section{SIMPULAN}

Hasil analisis memperlihatkan bahwa dari 69 responden, 52 responden (75,36\%) dikategorikan patuh dan 17 responden (24,64\%) sisanya dikategorikan tidak patuh. Hal ini disebabkan oleh beberapa faktor yaitu umur, jenis kelamin, tingkat pendidikan, pekerjaan, jenis obat yang dikonsumsi, lama menderita DM, dan dukungan keluarga.

\section{SARAN}

Guna meningkatkan kepatuhan minum obat pada pasien DM tipe 2, Puskesmas diharapkan dapat meningkatkan edukasi terkait pentingnya dukungan keluarga kepada keluarga pasien DM tipe 2 agar kepatuhan akan pengobatan khususnya minum obat dapat meningkat, seperti diingatkan minum obat, ditemani ke fasilitas kesehatan, diperhatikan apabila mengalami keluhan, membawa obat diabetes apabila bepergian, dan diingatkan untuk melakukan check up kesehatan.

\section{DAFTAR PUSTAKA}

Departemen Kesehatan Republik Indonesia. 2014. Infodatin Diabetes. Jakarta: Pusat Data dan Informasi Kementerian Kesehatan Republik Indonesia.

Dinas Kesehatan Kabupaten Tabanan. 2018.

Surveilans Terpadu Penyakit Puskesmas tahun 2018. Bali.

Dinas Kesehatan Provinsi Bali. 2017. Profil Kesehatan Provinsi Bali. Bali: Dinas Kesehatan.Bali.
Handayani I. B. 2012. Evaluasi Tingkat Kepatuhan Penggunaan Obat pada Pasien Diabetes Mellitus Tipe 2 Di Instalasi Rawat Jalan Rsud "X". Skripsi. Fakultas Farmasi Universitas Muhammadiyah Surakarta, Surakarta.

International Diabetes Federation. 2015. IDF Diabetes Atlas - Seventh Edition. Brussels, Belgium: International Diabetes Federation.

Kristianingrum, Budiyani. 2011. Dukungan Keluarga dan Kepatuhan Minum Obat Pada Orang Dengan Diabetes Melitus. Vol. 9, No.2, 55-58

Majed, H., Ismael, A., Khatlan, H., \& Shazly, M. 2014. Adherence of Type-2 Diabetic Patients to Treatment. Kuwait Medical Journal. 46(3): 225-232.

Mokolomban, Citra. 2018. Kepatuhan Minum Obat Pada Pasien Diabetes Melitus Tipe 2 Disertai Hipertensi dengan Menggunakan Metode MMAS-8. Jurnal Ilmiah Farmasi UNSRAT Volume (7) 4.

Pratita, N.D. 2012. Hubungan Dukungan Pasangan Dan Health Locus of Control Dengan Kepatuhan Dalam Proses Pengobatan Pada Penderita Diabetes Melitus Tipe 2. Surabaya: Universitas Surabaya.

Romadona, A. 2011. Pengaruh Konseling Obat terhadap Kepatuhan Pasien Diabetes Mellitus Tipe 2 di Poliklinik Khusus Rumah Sakit Umum Pusat Dr. M. Djamil Padang. Tesis Program Paska Sarjana. Universitas Andalas, Padang.

Srikartika V, Cahya A, \& Hardiati R. 2016. Analisis Faktor yang Mempengaruhi 
Arc. Com. Health Desember 2019

ISSN: 2527-3620

Vol. 6 No. 2 : 40 - 50

Kepatuhan Penggunaan Obat Pasien

Dengan Kepatuhan Berobat Pasien

Diabetes Mellitus Tipe 2. Jurnal

Diabetes Mellitus pada Praktek Dokter

Manajemen dan Pelayanan Farmasi,

Volume 6(3).

Keluarga di Kota Tomohon. Jurnal Ilmu

Kesehatan Masyarakat Unsrat. Volume

Tombokan V, AJM Rattu, \& Ch. R Tilaar.

2015. Faktor-faktor yang Berhubungan

$5(1)$. 